\title{
Development and use of a master health facility list: Haiti's experience during the 2010 earthquake response
}

\author{
Alyson Rose-Wood, ${ }^{a}$ Nathan Heard, ${ }^{b}$ Roody Thermidor, ${ }^{c}$ Jessica Chan, ${ }^{d}$ Fanor Joseph, ${ }^{e}$ Gerald Lerebours, ${ }^{e}$ \\ Antonio Zugaldia, ${ }^{d}$ Kimberly Konkel, ${ }^{f}$ Michael Edwards, ${ }^{e}$ Bill Lang, ${ }^{9}$ Carmen-Rosa Torres ${ }^{a}$
}

Collaboration between the Haitian government and NGOs after the 2010 earthquake contributed to a more accurate and complete master health facility list, which helped coordinate emergency response operations as well as strengthen the routine health information system. Open data and social networks facilitated the collection and sharing of health facility information and in maintenance of the list over time.

\begin{abstract}
Master health facility lists (MHFLs) are gaining attention as a standards-based means to uniquely identify health facilities and to link facility-level data. The ability to reliably communicate information about specific health facilities can support an array of health system functions, such as routine reporting and emergency response operations. MHFLs support the alignment of donor-supported health information systems with county-owned systems. Recent World Health Organization draft guidance promotes the utility of MHFLs and outlines a process for list development and governance. Although the potential benefits of MHFLs are numerous and may seem obvious, there are few documented cases of MHFL construction and use. The international response to the 2010 Haiti earthquake provides an example of how governments, nongovernmental organizations, and others can collaborate within a framework of standards to build a more complete and accurate list of health facilities. Prior to the earthquake, the Haitian Ministry of Health (Ministère de la Santé Publique et de la Population [MSPP]) maintained a list of public-sector health facilities but lacked information on privately managed facilities. Following the earthquake, the MSPP worked with a multinational group to expand the completeness and accuracy of the list of health facilities, including information on post-quake operational status. This list later proved useful in the response to the cholera epidemic and is now incorporated into the MSPP's routine health information system. Haiti's experience demonstrates the utility of MHFL formation and use in crisis as well as in the routine function of the health information system.
\end{abstract}

\section{INTRODUCTION}

A ccurate and regularly updated master health facility lists (MHFLs) are essential for effective planning, coordination, and delivery of health services, particularly in low- and middle- income countries with

\footnotetext{
a U.S. Department of Health and Human Services, Office of Global Affairs, Washington, DC, USA.

bU.S. Department of State, Humanitarian Information Unit, Washington, DC, USA.

'Ministère de la Santé Publique et de la Population, Unité de Planification et d'Evaluation, Port-au-Prince, Haiti.

${ }^{d}$ Pan American Health Organization, Emergency Operations Center, Washington, DC, USA.

eMEASURE Evaluation, Chapel Hill, NC, USA

fU.S. Department of Health and Human Services, Center for Faith-Based and Neighborhood Partnerships, Washington, DC, USA.

'Shoreland, Inc., Arlington, VA, USA

Correspondence to Alyson Rose-Wood (alyson.rosewood@gmail.com).
}

extensive external donor presence. MHFLs are also important during disasters because the lack of accurate, usable information is a major obstacle to effective disaster response. ${ }^{1,2}$ According to the World Health Organization (WHO), an MHFL is a complete list of health facilities in a country (both public and private) with a set of attributes to uniquely identify each facility, ${ }^{3}$ and it includes basic information about the facility's services and capacities.

With the release in 2012 of draft WHO guidance on the creation and governance of MHFLs, countries may be considering devoting resources to develop such lists. ${ }^{3}$ However, there are few documented experiences on the construction or use of MHFLs.

The earthquake in Haiti on January 12, 2010, underscored the need for countries to have an MHFL. At the time of the earthquake, the Haitian Ministry of 
Lack of accurate information is a major obstacle to effective disaster response.

\section{Master health facility lists help emergency response personnel know they are communicating about the same facility.}

\section{Broad representation in the Haiti Health Facilities Work Group facilitated coordination while minimizing duplication of efforts.}

Health (Ministère de la Santé Publique et de la Population [MSPP]) had a list of public-sector health facilities. However, the MSPP list contained little information about privately managed health facilities-a major part of the health delivery system in Haiti-and it lacked critical attributes needed to uniquely identify facilities.

During the earthquake response, the MSPP worked with the Haiti Health Facilities Work Group (Work Group), composed of a multinational group of organizations and governments, to develop a functioning MHFL, which proved useful during not only the earthquake response but also subsequent events such as the cholera outbreak.

This article reviews the development and use of the MHFL and provides a model for other countries interested in developing similar lists, which are increasingly needed to align donorsupported information systems with national health information systems.

\section{THE NEED FOR A COMPLETE HEALTH FACILITY LIST IN HAITI}

The epicenter of the 2010 Haiti earthquake was close to the most densely populated areas of Haiti, including the capital, Port-au-Prince. Approximately 250,000 buildings collapsed, including many hospitals. ${ }^{4}$ In the confusion that followed, there was uncertainty about the extent of damage to health facilities ${ }^{5}$ as well as a lack of information about the temporary clinics that were rapidly being set up. First responders were uncertain whether they were referring to the same health facility when communicating about the type, status, and capacity of facilities.

The MSPP is responsible for the health of the population and for the delivery of health-related services. ${ }^{6}$ At the time of the earthquake, the public health care system included more than 500 health institutions (approximately 30\% of the country's health facilities), ranging from community health clinics providing basic primary services to university hospitals. In addition, there were more than 250 nongovernmental organizations (NGOs) providing a substantial proportion of the primary health services. ${ }^{4,7}$

Prior to the earthquake, multiple, incomplete, and conflicting health facility information systems existed in Haiti; no entity served as a repository for an up-to-date, comprehensive master list. For example, the Haiti Health Information System (Système d'Information Sanitaire d'Haïti [HSIS]) functioned as a health management information system but was incomplete. Similarly, the Electronic Monitoring, Evaluation and Surveillance Interface for HIV-infected patients (MESI) collected data from public, and some private, health facilities in Haiti but primarily from sites receiving support from the U.S. President's Emergency Plan for AIDS Relief (PEPFAR).

\section{DEVELOPMENT AND USE OF HAITI'S MASTER HEALTH FACILITY LIST}

In the immediate aftermath of the earthquake, the U.S. Department of Health and Human Services (HHS) coordinated the formation of the Work Group in support of the MSPP. The first meeting of the Work Group took place via teleconference 5 days after the earthquake (on January 17, 2010) with representatives from U.S. federal agencies; academia; international, local, and Haitian diaspora NGOs; multilateral organizations; foundations; and businesses (Table 1). All Work Group activities were coordinated through conference calls and a shared web space. $^{8}$ Staff of the MSPP's Planning and Evaluation Unit (Unité de Planification et $d^{\prime}$ Evaluation [UPE]) were responsible for the HSIS; they participated in the Work Group and had final determination regarding edits to the MHFL.

Between January 2010 and August 2011, UPE staff collaborated with the Work Group to develop a single, comprehensive list of all public, private, and mixed (public and private) health facilities. The list was standardized, validated, and up-todate to guide and coordinate the health response to the earthquake. Senior MSPP leadership provided input and direction during several meetings in 2010.

The MHFL's initial purpose was to address the urgent need for a common list of health facilities in Haiti to ensure all emergency response personnel knew they were communicating about the same facility. The Work Group adapted guidelines on a minimum set of data elements necessary to uniquely identify a health facility, known as a signature domain, ${ }^{9}$ to inform the core set of information contained in the MHFL (Box). These elements included:

- A unique identifying code for each facility

- The facility name, address, and type

- The entity that manages/owns the facility

- Each facility's geographic coordinates 
TABLE 1. Organizational Participation in the Haiti Health Facilities Work Group by Category $(N=56)$

\section{Haitian Government}

Ministère de la Santé Publique et de la Population

\section{U.S. Government}

Department of Defense (DOD)

Department of Education

Department of Health and Human Services

Department of Homeland Security

Department of State

Peace Corps

United States Southern Command (DOD)

U.S. Agency for International Development

\section{Multilateral Organizations}

Geo-Operations Unit, United Nations

International Organization for Migration (IOM)

Office for the Coordination of Humanitarian Affairs, United Nations

World Health Organization/Pan American Health Organization

United Nations Development Programme

World Health Organization headquarters

\section{Academia}

Bloomberg School of Public Health, Johns Hopkins University

Center for Geographic Analysis, Harvard University

Emory University

The George Washington University

Institute for Global Leadership, Tufts University

Lincoln Laboratory, Massachusetts Institute of Technology

Mailman School of Public Health, Columbia University

\section{Foundations}

Clinton Foundation

Google Foundation

\section{NGOs and Private Consultants}

Arkemie

Association of Haitian Physicians Abroad, Florida Chapter

Baertracks

Christian Connections for International Health

Christian Medical and Dental Associations

Citizen Command Center Database Team, Citizen Action Team

Communibuild Technologies

CrisisCommons

DirectRelief

Evotech, Inc.

FortiusOne, Inc.

Global Health Action

Haitian Mental Health Network

Haiti Village Health

Humanitarian Medical Aid Direct Relief

ICF International

IMA World Health

InSteDD

InterAction

Logistics for Health

MEASURE Evaluation

Medical Mission Exchange

OpenStreetMap

Project Medishare for Haiti

ReliefWeb

Sahana Software Foundation

Shoreland, Inc.

Synergist Technology Group, Inc.

Thermopylae Sciences + Technology

Ushahidi

World Cares Center

World Concern

although IOM is not part of the UN system, it works very closely with the UN specialized agencies and is part of UN Country Teams around the world. 


\begin{abstract}
Haiti's master health facility list was posted to a public Google Site to increase the chances of it being used and updated over time.
\end{abstract}

\section{Online dissemination of the MHFL helped integrate the unique health facility codes into other data collection efforts.}

\section{Haiti's master health facility list developed for the earthquake response was eventually incorporated into the routine health information system.}

\section{BOX. Recommended Data Elements} for Master Health Facility Lists

Signature Domain (set of data elements that do not change significantly over time)

- Unique identifier

- Facility name

- Facility type

- Ownership/managing authority

- Location/address

- Administrative units

- Geographic coordinates

- Operational status

- Year data collected

Service Domain (set of data elements that provide some basic information on a facility's services and capacities)

- Core basic services offered

- Number of core medical personnel

- Number of inpatient and maternity beds available

$$
\begin{aligned}
& \text { Adapted from the World Health } \\
& \text { Organization. }
\end{aligned}
$$

A codebook for the signature domain fields was created building on codes created by the Institut Haïtien de Statistique et d'Informatique (Supplementary Appendix).

The first iteration of the MHFL that contained only the signature domain fields was created on January 29, 2010, by blending the MSPP's existing HSIS health facility list with partial lists, volunteered geographic information, and local knowledge on the post-earthquake status of health facilities in order to produce a more comprehensive list (Table 2). To improve functionality, the Work Group included standardized names of each facility in English, French, and Haitian Creole. The Work Group verified information by soliciting feedback on a publicly posted version of the MHFL coupled with direct outreach to health facilities by phone or inperson when possible.

In keeping with United Nations recommendations on the coordination of information during humanitarian emergencies, the Pan American Health Organization's Emergency
Operations Center (PAHO EOC) took a lead role in managing the MHFL. ${ }^{10,11}$ The PAHO EOC published the first iteration of the MHFL and codebook to a public Google Site. ${ }^{12}$ Posting the list to an open website increased the likelihood that the MHFL and its codes would be used and that those involved in the response would provide feedback to note missing facilities and to correct errors. Contributors through the site included NGOs, members of the Crisis Mappers Network, $^{13}$ and health facility staff. Between January 29 and March 18, 2010, WHO/PAHO released 6 updated versions of the Master List. Each version of the MHFL included new health facilities, fewer duplicates, and corrected variable values (Table 2 ).

The MHFL was used widely in the initial earthquake response. In addition to the Google Site, a link to the list was posted to many of the information portals that proliferated following the earthquake. The MHFL was also used as the reference data set for health facilities in the OpenStreetMap (OSM) platform. ${ }^{14,15}$ OSM updated its health facility layer with each of the 7 versions of the list. ${ }^{16}$

As the initial effort transitioned from emergency response to reconstruction, stewardship of the MHFL was transferred to Shoreland, Inc., during April 2010. ${ }^{17}$ Following the cholera outbreak in Haiti in October 2010, fields for cholera treatment centers (CTCs) and cholera treatment units (CTUs) were added. The MSPP used the MHFL to determine which communities lacked health facilities so CTCs and CTUs could be installed to provide care to the affected population. ${ }^{18}$

In September 2011, the MSPP incorporated data from the MHFL into its routine health information system, which collects information on key services provided and human resources present at each facility. The MHFL formed the basis of the Liste des Institutions Sanitaires, the MSPP's listing of health facilities in the country, ${ }^{19}$ which is an updated and more robust version of the HSIS. It was also integrated into the Carte Sanitaire, the MSPP's service delivery and infrastructure status database. ${ }^{20,21}$ MEASURE Evaluation and the MSPP'S UPE continue to work collaboratively to update and validate the Liste des Institutions Sanitaires in coordination with the directors of statistics and epidemiology within each of the 10 departments. Health facilities and field hospitals can now be uniquely identified. However, some duplicates and data quality issues remain. 
TABLE 2. Evolution of the Haiti Master Health Facility List

\begin{tabular}{|c|c|c|c|}
\hline Version & Date & Host & Edits/Additions \\
\hline $\begin{array}{l}\text { Pre- } \\
\text { earthquake }\end{array}$ & Before 2010 & $\begin{array}{l}\text { The HSIS list was } \\
\text { available online } \\
\text { through the HSIS } \\
\text { website. }\end{array}$ & Last updated in 2009. \\
\hline 1 & $\begin{array}{l}\text { January 29, } \\
2010\end{array}$ & PAHO & $\begin{array}{l}\text { Information on health facilities from } \\
\text { the HSIS was merged with other lists } \\
\text { creating a total of }+/-1,260 \text { records. } \\
\text { The } 2009 \text { HSIS health facility list } \\
\text { included the following fields: rank } \\
\text { (a number assigned to the facility } \\
\text { according to when it was created } \\
\text { in the commune); name of the } \\
\text { department, district, and commune } \\
\text { where the facility is located; name } \\
\text { of the facility; category (e.g., } \\
\text { dispensary, hospital); and type } \\
\text { (public, private, or mixed). }\end{array}$ \\
\hline 2 & $\begin{array}{l}\text { February } 9 \\
2010\end{array}$ & PAHO & $\begin{array}{l}7 \text { new health facilities were } \\
\text { added. }\end{array}$ \\
\hline
\end{tabular}

New fields were added for damage and operational status information; 39 new health facilities were added (including field hospitals); and 41 duplicate records were removed.

63 new health facilities were added; 19 duplicate records were removed; and metadata was updated.

5 February 26, PAHO

HealthC_IDs (unique

identification codes) were

added to facilities that

previously lacked one.

6 March 11, PAHO

Region, commune, and department

IDs in the MHFL were matched to the MSPP_2010 list; official facility names were added; inaccurate values for the various codes used by the MSPP were corrected; geocodes of numerous MSPP sites were corrected; and about 20 duplicate records were removed. This version included all 2010 MSPP health facilities.

No entity served as a repository for an MHFL. The HSIS became the basis for the MHFL, but it was incomplete; it did not cover the non-public sector and had variable reporting from the 750 public health facilities in it.

Information sources included: HSIS, MESI, USAID, PAHO, PEPFAR, UNOCHA, the Sahana Foundation, MINUSTAH, and Ushahidi.

All HealthC_IDs from version 4 remained unchanged, but changes were made to the algorithm used to generate new unique identifiers in the metadata (Supplementary Appendix).

New information received post-earthquake from MEASURE Evaluation on behalf of the Haitian MSPP was incorporated into the new MHFL. 
TABLE 2 (continued).

\begin{tabular}{|c|c|c|c|c|}
\hline Version & Date & Host & Edits/Additions & Comments \\
\hline 7 & $\begin{array}{l}\text { March 18, } \\
2010\end{array}$ & $\begin{array}{l}\text { PAHO. Stewardship } \\
\text { transferred to } \\
\text { Shoreland, } \\
\text { Inc., in April 2010, } \\
\text { and version } 7 \text { was } \\
\text { republished on } \\
\text { Shoreland's Travax } \\
\text { system. }{ }^{17}\end{array}$ & $\begin{array}{l}50 \text { duplicates were removed } \\
\text { and more than } 80 \text { new health } \\
\text { facilities were added. } \\
\text { CATEGORIE, TYPE, and } \\
\text { SANTE_ID fields were } \\
\text { updated with the latest } \\
\text { information } \\
\text { from the MSPP. }\end{array}$ & $\begin{array}{l}\text { When the list was republished } \\
\text { on the Travax site, }{ }^{17} \text { a field } \\
\text { for cholera treatment centers } \\
\text { was added. }\end{array}$ \\
\hline $\begin{array}{l}\text { Liste des } \\
\text { Institutions } \\
\text { Sanitaires }\end{array}$ & $\begin{array}{l}\text { Summer } \\
2011\end{array}$ & MSPP & $\begin{array}{l}\text { Health facilities and field hospitals can } \\
\text { now be uniquely identified. Data are } \\
\text { updated and validated through self- } \\
\text { reporting from facilities and data } \\
\text { collection efforts by the MSPP and } \\
\text { partners. Some duplicates and data } \\
\text { quality issues remain. The list does not } \\
\text { include information on mobile clinics } \\
\text { (those that are still operational). }\end{array}$ & $\begin{array}{l}\text { The MSPP incorporated the } \\
\text { MHFL for a key input to its } \\
\text { routine health information } \\
\text { system. The MHFL forms the } \\
\text { basis of the Liste des } \\
\text { Institutions Sanitaires } \\
\text { integrated into the MSPP's is } \\
\text { service delivery and }_{\text {infrastructure database. }}^{20,21} \\
\text { It is used on an ongoing basis } \\
\text { to measure health service } \\
\text { coverage. }\end{array}$ \\
\hline
\end{tabular}

Abbreviations: HSIS, Haiti Health Information System (Système d'Information Sanitaire d'Haïti); MESI, Electronic Monitoring, Evaluation and Surveillance Interface for HIV-infected patients; MHFL, master health facility list; MINUSTAH, United Nations Stabilization Mission in Haiti; MSPP, Haitian Ministry of Health (Ministère de la Santé Publique et de la Population); PAHO, Pan American Health Organization; PEPFAR, U.S. President's Emergency Plan for AIDS Relief; UNOCHA, United Nations/Office for the Coordination of Humanitarian Affairs; USAID, U.S. Agency for International Development.

Ministries of
health play an
essential role
in creating,
managing, and
verifying data for
master health
facility lists.

\section{Challenges}

Multiple Sources of Information

In many countries, information about health facilities exists within stand-alone systems designed for discrete purposes. Lack of standardized naming conventions and codes unique to each facility but common across information systems introduces ambiguity to facility identity when comparing or consolidating multiple lists, resulting in duplications. ${ }^{27}$ It may be difficult to link multiple sources of information to support decisionmaking under normal circumstances, let alone during a disaster. ${ }^{28,29}$

\section{Lack of Procedures}

Ministries of health hold an essential ownership, management, verification, and communication function for MHFLs. Several dynamics explain why many ministries of health do not have an adequate MHFL. Procedures for regular updates may be lacking, causing information to easily become out-of-date. It is also common for facility-based health services in low- and middleincome countries to involve a complex array of multilateral, bilateral, public, and private for-profit and not-for-profit organizations. ${ }^{30}$ These organizations typically maintain information about the health facilities they support. However, there may be little or no information sharing among these groups or with the ministry of health. This is 
certainly the case in Haiti, where coordination between the government and the NGO community has historically been poor. ${ }^{31}$

\section{Coordination}

Haiti's MHFL provides a national-level view of Haiti's health facility infrastructure. The MHFL is updated at one central location by the UPE and consolidates information from the MSPP, WHO/ PAHO, HHS/Centers for Disease Control and Prevention (CDC), the United States Agency for International Development (USAID), and the NGO community. Yet some coordination issues remain. Although publically available, there is a gap in regular updates to the MHFL and ongoing quality control efforts are necessary to maintain and improve the quality of the data and to remove duplicate records.

\section{Opportunities}

\section{Open Data and Social Networks}

When MHFLs do not exist or are incomplete, responders during crises will need to collect data for immediate purposes. In the case of Haiti, open data, social networks, and volunteered geographic information were major factors that facilitated information flow about health facilities during the earthquake response. ${ }^{15,32-37}$ In addition, multiple organizations collected information directly from health facilities following the earthquake. However, lack of coordination among these organizations created confusion and overwhelmed health facility personnel. A pre-existing list that was updated at a central location could have mitigated this situation.

\section{Quality Control Processes}

The process of integrating data from multiple sources can spawn a proliferation of duplication and errors. For multi-sourced data to be widely accepted as reliable information, quality control processes must be in place to rapidly screen and verify data before it becomes official data. In the case of Haiti, central-level engagement of officers within the health system provided a quality check of the information in each of the iterations of the MHFL. However, validation can best occur with the engagement of appropriate staff at more local levels of health system administration.

\section{Free, Online Access}

Web-based repositories for MHFLs, such as Haiti's or Kenya's repositories, ensure that lists are available when needed and also can provide a platform for the maintenance of facility data over time. ${ }^{3,21,38}$ Ease of access to health facility lists increases the likelihood of data use. Data users and generators can then feed information to the system to create a cycle that should improve list completeness and quality over time.

The draft guidance from WHO on how to create an MHFL outlines a standardized process and provides WHO-endorsed standards for data format and data governance. ${ }^{3}$ The WHO guidelines also provide information on how the content of an MHFL can be made accessible and maintained over time.

\section{CONCLUSION}

Having an accurate, regularly updated, and freely accessible national MHFL is important for effective routine planning and the delivery of health care services. During the 2010 Haiti earthquake response, the creation of a functioning MHFL proved useful for coordination and reconstruction efforts including subsequent events such as the cholera outbreak. A pre-populated data set that was comprehensive, accurate, and relatively up-todate would have greatly facilitated initial relief efforts. Recognizing that disasters can occur anywhere and that accurate data are critical for effective response, countries without lists should develop and maintain an MHFL. Modest efforts in this area could greatly enhance the ability to mount a rapid, coordinated, and effective response.

\section{Acknowledgments: The authors would like to acknowledge the contributions of the MSPP; the entire Haiti Health Facilities Work Group; the Google Foundation; Eric Schmeckpeper, U.S. Forest Service; Stephane Morriseau, USAID-Haiti; Alicia A. Livinski, National Institutes of Health Library; Craig Shapiro, HHS/OGA; Jon Andrus and Cuauhtémoc Ruiz, WHO/PAHO; Nora Purcell, Johns Hopkins University; and Kathy Cavallaro, Barbara Marston, and Daphne Moffett, HHS/CDC.}

Competing Interests: None declared.

\section{REFERENCES}

1. McDonnell SM, Perry HN, McLaughlin B, McCurdy B, Parrish RG. Information for disasters, information disasters, and disastrous information. Prehosp Disaster Med. 2007;22(5):406413. Medline

2. Nickerson J. Views From Beyond the OR [blog on the Internet]. Ottawa (ON): Jason Nickerson. [2012] - . Mapping health facilities in crises: reflections and directions; 2012 Jun 6. [cited 2013 Nov 22]; [about 3 screens]. Available from: http://www. jasonnickerson.ca/blog/2012/06/mapping-health-facilities-incrises-reflections-and-directions/

3. World Health Organization (WHO). Creating a master health facility list [draft]. Geneva: WHO; 2012. Available from: http:// www.who.int/healthinfo/systems/WHO_CreatingMFL_draft.pdf

\section{Open data, social networks, and volunteered geographic information are playing an increasing role in crisis response.}


4. World Health Organization (WHO). Culture and mental health in Haiti: a literature review. Geneva: WHO; 2010. Available from: http://www.who.int/mental_health/publications/culture mh_Haiti_2010/en/

5. Government of the Republic of Haiti. Haiti earthquake postdisaster needs assessment: assessment of damage, losses, general and sectoral needs. Port-au-Prince (Haiti): Government of the Republic of Haiti; 2010. Available from: http:// documents.worldbank.org/curated/en/2010/03/16394500/ haiti-earthquake-pdna-post-disaster-needs-assessmentassessment-damage-losses-general-sectoral-needs

6. World Health Organization (WHO) [Internet]. Geneva: WHO; c2014 [cited 2013 Nov 22]. Countries: Haiti; [about 1 screen] Available from: http://www.who.int/countries/hti/en/index. $\mathrm{html}$

7. World Bank. Social resilience and state fragility in Haiti: a country social analysis. Washington (DC): World Bank; 2006. Available from: http://siteresources.worldbank.org/ SOCIALANALYSIS/1 104894-1115795935771//20938696/ Haiti_CSA.pdf

8. MAX.gov [Internet]. Washington (DC): Office of Management and Budget; [cited 2013 Nov 22]. Available from: https://max. omb.gov/maxportal/home.do

9. Health Facility Technical Working Group. The signature domain and geographic coordinates: a standardized approach for uniquely identifying a health facility. Chapel Hill (NC): University of North Carolina at Chapel Hill, Carolina Population Center, MEASURE Evaluation; 2007. Available from: http://www.cpc. unc.edu/measure/publications/wp-07-91

10. World Health Organization (WHO). Health cluster guide: a practical guide for country-level implementation of the health cluster. Geneva: WHO; 2009. Available from: http://www. who.int/hac/global_health_cluster/guide/en/

11. Thieren $M$. Health information systems in humanitarian emergencies. Bull World Health Organ. 2005;83(8):584-589. Medline

12. Haiti Health Facilities [Internet]. [Milwaukee (WI)]: Shoreland; [cited 2013 Nov 22]. Available from: http://sites.google.com/ a/netspective.org/haiti-health-facilities/home

13. Crisis Mappers: The Humanitarian Technology Network [Internet]. [place unknown]: Patrick Meier; c2014 [cited 2013 Nov 22]. Available from: http://crisismappers.net/

14. WikiProject Haiti [Internet]. West Midlands (UK): OpenStreetMap; [last modified 2012 Apr 12]. WikiProject Haiti/Status/Hospitals; [last modified 2011 Nov 5; cited 2013 Nov 22]; [about 7 screens]. Available from: http://wiki. openstreetmap.org/wiki/WikiProject_Haiti

15. Soden R, Palen L. From crowdsourced mapping to community mapping: the post-earthquake work of OpenStreetMap Haiti. In: COOP 2014 - Proceedings of the $11^{\text {th }}$ International Conference on the Design of Cooperative Systems; May 27-30, 2014; Nice, France. Geneva: Springer; 2014. p. 311-326. Available from: https://www.cs.colorado.edu/ palen/palen_papers/ HaitiCOOP_Final.pdf

16. HaitiData [Internet]. Washington (DC): World Bank Group. Haiti health facilities before 2010 (structures de santé avant 2010), OSM [15.03.2011] - point. 2012 Jun 2 [cited 2013 Nov 22]; [about 2 screens]. Available from: http://haitidata.org/layers/ cnigs.spatialdata:hti_structure_health_facilities_ante_2010_ osm_15032011

17. Shoreland, Inc. [Internet]. Milwaukee (WI): Shoreland; c2014. Travax: Haiti health facilities. [cited 2013 Nov 22]. Available from: https://www.travax.com/resources
18. United Nations, Office for the Coordination of Humanitarian Affairs (OCHA). Haiti: cholera snapshot. [New York]: OCHA; 2012. Available from: http://reliefweb.int/sites/reliefweb.int/ files/resources/map_2467.pdf

19. Unité de Planification et d'Evaluation (UPE). Liste des institutions sanitaires. Port-au-Prince (Haiti): Ministère de la Santé Publique et de la Population [Haiti], Projet d'Appui au Développement du Système de Santé en Haiti; 2011.

20. Unité de Planification et d'Evaluation (UPE). Rapport de la carte sanitaire du pays. Port-au-Prince (Haiti): Ministère de la Santé Publique et de la Population [Haiti]; 2011.

21. Ministere de la Sante Publique et de la Population [Haiti]. Cartographie sanitaire d'Haiti. Port-au-Prince (Haiti): Unite de Planification et d'Evaluation; 2010. Available from: http://www. mspp.gouv.ht/cartographie/index.php

22. Rosero-Bixby L. Spatial access to health care in Costa Rica and its equity: a GIS-based study. Soc Sci Med. 2004;58(7):12711284. CrossRef. Medline

23. Troseli M, Fanton D. [Computerization and the importance of information in health system, as in health care resources registry]. Acta Med Croatica. 2005;59(3):251-257. Croatian. Medline

24. Pan American Health Organization (PAHO). Manual logistical management of humanitarian supply. Washington (DC): PAHO; 2000. Available from: http://www.disasterinfo.net/SUMA/english/software/manuals/ MISEManualEnglish.pdf

25. AbouZahr C, Boerma T. Health information systems: the foundations of public health. Bull World Health Organ. 2005;83(8):578-83. Medline

26. Skinner R. Integrating location into hospital and healthcare facility emergency management. J Healthc Prot Manage. 2011;27(1):31-35. Medline

27. Noor AM, Alegana VA, Gething PW, Snow RW. A spatial national health facility database for public health sector planning in Kenya in 2008. Int J Health Geogr. 2009;8(1):13. CrossRef. Medline

28. Stansfield SK, Walsh J, Prata N, Evans T. Information to improve decision making for health. In: Jamison DT, Breman JG, Measham AR, Alleyne G, Claeson M, Evans DB, et al., editors. Disease control priorities in developing countries. 2nd ed. Washington (DC): World Bank; 2006. Chapter 54. Available from: http://www.ncbi.nlm.nih.gov/books/NBK11731/

29. Health Metrics Network. Framework and standards for country health information systems. Geneva: World Health Organization; 2008. Available from: http://www.who.int/ healthmetrics/documents/hmn_framework200803.pdf

30. McCoy D, Chand S, Sridhar D. Global health funding: how much, where it comes from and where it goes. Health Policy Plan. 2009;24(6):407-417. CrossRef. Medline

31. De Córdoba J. Aid spawns backlash in Haiti. The Wall Street Journal [Internet]. 2010 Nov 12 [cited 2014 Jul 19]; [about 4 p]. Available from: http://online.wsj.com/news/articles/ SB10001424052702304023804575566743115456322

32. Sarcevic A, Palen L, White J, Starbird K, Bagdouri M, Anderson K. "Beacons of hope" in decentralized coordination: learning from on-the-ground medical Twitterers during the 2010 Haiti Earthquake. In: CSCW'12 proceedings of the ACM 2012 Conference on Computer Supported Cooperative Work; February 11-12, 2012; Seattle, WA; 2012. p. 47-56. Available from: http://epic.cs.colorado. edu/wp-content/uploads/Sarcevic-et-alHaitiMedicalTwitterers.pdf 
33. Goodchild MF. Citizens as sensors: the world of volunteered geography. GeoJournal. 2007;69(4):211-221. CrossRef

34. Liu SB, Palen L. The new cartographers: crisis map mashups and the emergence of neogeographic practice. Cartogr Geogr Inf Sci. 2010;37(1):69-90. CrossRef

35. Heinzelman J, Waters $C$. Crowdsourcing crisis information in disaster-affected Haiti: special report. Washington (DC): United States Institute for Peace; 2010. Available from: http://www.usip. org/publications/crowdsourcing-crisis-information-in-disasteraffected-haiti

36. Zook M, Graham M, Shelton T, Gorman S. Volunteered geographic information and crowdsourcing disaster relief: a case study of the Haitian earthquake. World Med Health Policy. 2010;2(2):6-32. CrossRef

37. Harvard Humanitarian Initiative. Disaster relief 2.0: the future of information sharing in humanitarian emergencies. Washington (DC): UN Foundation; 2011. Co-published by Vodafone Foundation Technology Partnership. Available from: http://www.unfoundation.org/ news-and-media/publications-and-speeches/disaster-relief-2report.html

38. Ministry of Health (MOH) [Kenya] [Internet]. Nairobi (Kenya): $\mathrm{MOH}$; c2011. eHealth-Kenya facilities; 2013 [cited 2013 Nov 22]. Available from: http://www.ehealth.or.ke/ facilities/

\section{Peer Reviewed}

Received: 2014 Feb 17; Accepted: 2014 Jul 16; First published online: 2014 Aug 5

Cite this article as: Rose-Wood A, Heard N, Thermidor R, Chan J, Joseph F, Lerebours G, et al. Development and use of a master health facility list: Haiti's experience during the 2010 earthquake response. Glob Health Sci Pract. 2014;2(3):357-365. http://dx.doi.org/10.9745/GHSP-D-14-00029.

(c) Rose-Wood et al. This is an open-access article distributed under the terms of the Creative Commons Attribution License, which permits unrestricted use, distribution, and reproduction in any medium, provided the original author and source are properly cited. To view a copy of the license, visit http:// creativecommons.org/licenses/by/3.0/ 